University of Louisville

ThinkIR: The University of Louisville's Institutional Repository

Electronic Theses and Dissertations

$5-2020$

\title{
Marriage and cohabitation in the United States: the effects of union type on relationship quality.
}

Courtney M. Lush

University of Louisville

Follow this and additional works at: https://ir.library.louisville.edu/etd

Part of the Family, Life Course, and Society Commons

\section{Recommended Citation}

Lush, Courtney M., "Marriage and cohabitation in the United States: the effects of union type on relationship quality." (2020). Electronic Theses and Dissertations. Paper 3466.

https://doi.org/10.18297/etd/3466

This Master's Thesis is brought to you for free and open access by ThinkIR: The University of Louisville's Institutional Repository. It has been accepted for inclusion in Electronic Theses and Dissertations by an authorized administrator of ThinkIR: The University of Louisville's Institutional Repository. This title appears here courtesy of the author, who has retained all other copyrights. For more information, please contact thinkir@louisville.edu. 


\title{
MARRIAGE AND COHABITATION IN THE UNITED STATES: THE EFFECTS OF UNION TYPE ON RELATIONSHIP QUALITY
}

\author{
By \\ Courtney M. Lush \\ B.A., Eastern Kentucky University, 2018 \\ A Thesis Submitted to the Faculty of the \\ College of Arts and Sciences of the University of Louisville \\ in Partial Fulfillment of the Requirements \\ for the Degree of \\ Master of Arts \\ In Sociology \\ Department of Sociology \\ University of Louisville \\ Louisville, Kentucky
}

May 2020 

MARRIAGE AND COHABITATION IN THE UNITED STATES: THE EFFECTS OF UNION TYPE ON RELATIONSHIP QUALITY

\section{By}

Courtney Lush

B.A., Eastern Kentucky University, 2018

A Thesis Approved on

April 16, 2020

by the following Thesis Committee:

Dr. Hiromi Taniguchi

Dr. Karen Christopher

Dr. Patricia Gagne 


\section{ABSTRACT \\ MARRIAGE AND COHABITATION IN THE UNITED STATES: THE EFFECTS OF UNION TYPE ON RELATIONSHIP QUALITY}

Courtney M. Lush

April 16, 2020

Using national dyadic data from the 2010 Married and Cohabiting Couples (MCC) survey, I examine the effects on relationship quality of union type: "direct marriage", "marriage after cohabiting", "cohabitation with plans to marry", "cohabitation with no marriage plan". In addition, I examine whether these effects are different for men and women. Consistent with prior research, I found that cohabitors without plans to marry report the lowest levels of relationship quality and those who married directly report the highest levels of relationship quality. Also consistent with prior research, I find no gendered differences in the effect of union type on relationship quality for those who are married. However, in cohabiting union, the effects of union type on relationship quality are stronger for women than for men. This study adds to the growing literature by showing that the effects of union type on relationship quality are gendered for cohabiting relationships. 


\section{TABLE OF CONTENTS}

PAGE

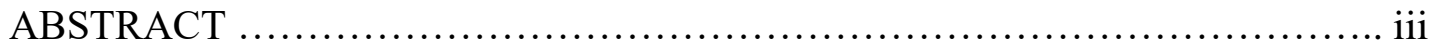

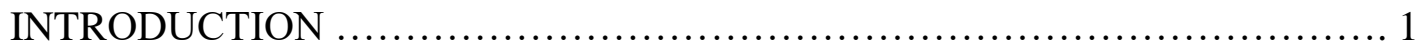

LITERATURE REVIEW ............................................. 3

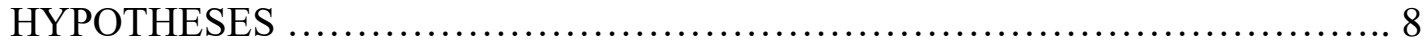

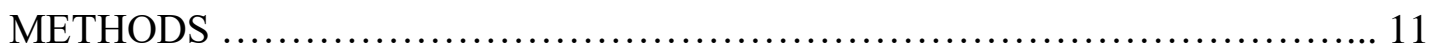

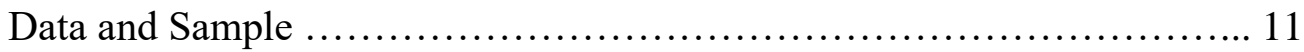

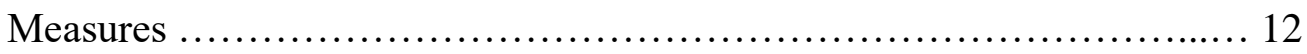

Analytic Strategy ............................................... 15

RESULTS ............................................................. 17

Descriptive Results .......................................... 17

Regression Results ............................................. 23

Gendered Differences....................................... 28

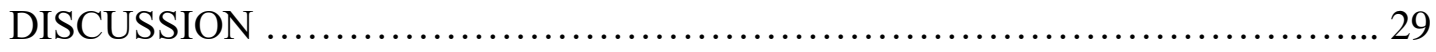

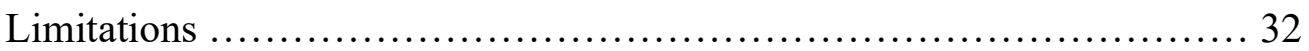

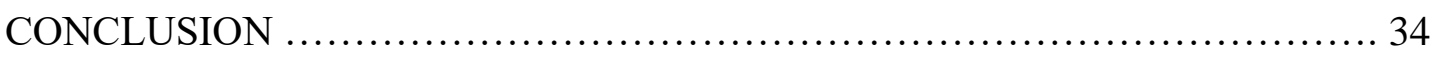

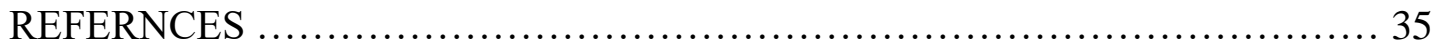

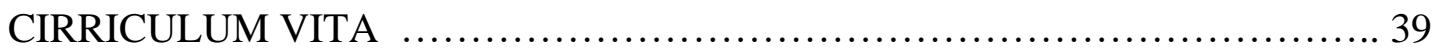




\section{INTRODUCTION}

Cohabitation has been on the rise in the United States for the past several decades. It has become both a model path into marriage as well as an acceptable alternative to marriage (Manning \& Smock, 2002; Huang, et al, 2012). Due to its growing popularity, cohabitation has become less selective (Brown, Manning, \& Payne, 2017). In other words, those who cohabit are not as distinguishable, in terms of various characteristics, from those who do not cohabit. Alternatively, those who do not cohabit are now becoming a highly selective group (Brown, Manning, \& Payne, 2017). With cohabitation becoming more prominent in our society, numerous studies have been conducted to examine how this increase in cohabitation affects the overall contemporary family life course.

This study draws on the work of Brown et al. (2017) to analyze the effect of union type on relationship quality for both men and women. This is a secondary analysis of data obtained from the Married and Cohabiting Couple (MCC) survey administered in 2010. These data provide information on heterosexual couples only. Following the lead of Brown et al., I analyze the effect of union type on both relationship happiness and relationship disillusionment for men and women. I analyze union type using four categories: those who married without cohabiting, those who married after cohabiting, 
those who are cohabiting with plans to marry, and those who are cohabiting without plans to marry. Using seemingly unrelated (SUR) regression, I analyze the effects of union type on both relationship happiness and relationship disillusionment of men and women. I also examine how union type effects relationship quality differently for men and women. The results of this study add to the continually growing literature focusing on the state of intimate relationships in the U.S. given the recent rise in cohabitation. 


\section{LITERATURE REVIEW}

The United States has experienced a dramatic rise in cohabitation in the past several decades. Almost three fourths of young adults have lived in a cohabiting union at some point in their lifetime (Brown, Manning, \& Payne, 2017). The majority of declines in the proportion of individuals married by age 25 in the past few decades are offset by increasing rates of cohabitation (Brown, 2000). In addition, the more recent declines in rates of individuals who remarry are fully compensated for by the increasing rates of cohabitation (Brown, 2000). Cohabitation is now a customary part of the American courtship process and the ideal path into marriage (Manning \& Smock, 2002; Huang, et al, 2012). Cohabitation has also increased as an alternative to marriage (Manning \& Smock, 2002; Cherlin, 2004). Marriage is now a choice, not a requirement, for adults who want intimacy, companionship, and children (Cherlin, 2004). Those who choose not to marry can enter in a "meretricious" relationship instead - a relationship that is stable and martial-like but both parties cohabit with the knowledge that a lawful marriage does not exist between them (Thorton, Axinn, \& Xie, 2007). This recent rise in cohabitation and subsequent decrease in marriage indicate that the practical importance of marriage is decreasing (Cherlin, 2004).

With cohabitation becoming such a prominent phenomenon in American society, a vast amount of research has been conducted to examine the various characteristics and 
implications of cohabitation. The majority of these studies have analyzed the various aspects of relationship quality and compared them between married and cohabiting couples. Several studies find that in general, cohabitors report poorer relationship quality than their married counterparts (Brown \& Booth, 1996; Brown, Manning, \& Payne, 2017.) These studies argue that the biggest difference in relationship quality is between those who marry directly and those who cohabit without plans to marry (Brown \& Booth, 1996; Brown, Manning, \& Payne, 2017).

One possible explanation for this difference in relationship quality between married and cohabiting couples is differing levels of religiosity (Heaton \& Pratt, 1990; Arland, Axinn, \& Hill, 1992; Stanely, Whitton, \& Markman, 2004). Individuals from less religious families have a higher rate of entering cohabitations and more frequently cohabit as a substitute for marriage (Arland, Axinn, \& Hill, 1992). In addition, cohabitation often decreases religiosity while marriage increases religious participation (Arland, Axinn, \& Hill, 1992). Since religiosity is positively correlated with happiness, this could be a reasonable explanation for the lower relationship quality seen among cohabitors.

On the other hand, this phenomenon could possibly be the result of the increasing importance of marriage as a symbol of status (Cherlin, 2004). For example, marriage is increasingly important in explaining the rising inequality in the U.S. given higher income people are more likely to marry other higher income people (Cherlin, 2004). Therefore, the higher relationship quality experienced by those in marriages compared to those in cohabiting unions may be the result of higher household income and less financial stress. 
Another relationship characteristic that tends to have a significant effect on relationship quality is the presence of children. Previous studies have found that the presence of children is negatively associated with relationship quality (Nock, 1995; Skinner et al., 2002). Similarly, the absence of children was associated with higher levels of relationship happiness and lower levels of relationship disillusionment (Brown et al., 2017). In addition, the presence of children is often associated with lower levels of relationship dissolution among cohabitors (Brown \& Booth, 1996). Therefore, despite being unhappy or unsatisfied, cohabitors are likely to remain in their current union for the sake of their children. This could result in a higher number of unhappy cohabiting unions.

One study in particular conducted by Susan Brown, Wendy Manning, and Krista Payne stands out among the others as it analyzed relationship quality between four union types: married without premarital cohabitation, married with premarital cohabitation, cohabiting with plans to marry, and cohabiting without plans to marry (2017). This categorization allowed for diversity within the two broad divisions of marriage and cohabitation and also eliminated a degree of "blurriness" that has been placed on the line drawn between the two union types (Brown et al. 2017). The data for this study was taken from the 2010 Married and Cohabiting Couples (MCC) survey (Brown et al. 2017).

The study conducted by Brown et al. also stands out among other similarly conducted studies because it analyzed relationship quality through two measures: happiness and disillusionment (2017). By using these two measures, the study analyzed both positive and negative indicators of relationship quality (Brown et al., 2017). The "happiness" variable was derived from a survey item which asked respondents to rate their happiness with their relationship on a 10-point scale (Brown et al., 2017). The 
"disillusionment" variable was derived from multiple survey items that ask respondents questions regarding perceived change in their relationship qualities such as love and affection (Brown et al., 2017).

The most significant feature of this study is that it uses couple or dyadic data, meaning that both partners in the couple were included in the sample. This is the ideal standard for relationship quality research. The study then used seemingly unrelated regression (SUR) models to analyze the effect that union type has on relationship happiness and disillusionment (Brown et al., 2017). The model included the following control variables: respondent education, respondent race, household income, relationship duration, presence of children, educational heterogamy, employment heterogamy, age heterogamy, and race heterogamy (Brown et al., 2017). The analytic sample was restricted to couples who had been together for no more than 10 years (Brown et al., 2017). The study found that relationship quality varied by relationship type for both men and women (Brown et al., 2017). Among women, relationship happiness was highest among those who married directly, followed by marrieds who premaritally cohabited, cohabitors with plans to marry, and finally cohabitors without plans to marry (Brown et al., 2017). For men, relationship happiness was higher among marrieds than cohabitors, however happiness did not vary between the two types of marrieds (Brown et al., 2017). Men who were cohabiting without plans to marry expressed less relationship happiness than all other union types (Brown et al., 2017). Relationship disillusionment in women was lowest among women who married directly, followed by married women who cohabited premaritally, cohabitors with plans to marry, and finally cohabitors without plans to marry (Brown et al., 2017). For men, the same trend emerged. (Brown et al., 
2017). Brown et al. concluded that this effect of union type on relationship happiness and relationship disillusionment may be caused by the lack of a universal meaning of cohabitation (2017). Cohabitation can have vastly different meanings various racial, ethnic, and social class groups (Brown et al., 2017). This can lead to unmet expectations and conflicts in cohabiting unions (Brown et al., 2017).

I also draw on the work of Jeffery Jackson, Megan Oka, Richard Miller, and Ryan Henry to analyze gender differences in the effect of union type on relationship quality (2014). Jackson et al. conducted a meta-analysis of studies examining marriage relationship quality to test the assumption that women report lower levels of relationship quality than men (2014). Their meta-analysis included 226 independent samples found in articles published between 1970 and 2009 (Jackson et al, 2014). They distinguished between samples including dyadic data, or couple data, and samples including nondyadic samples, or individual non-couple data. They found that (1) when using dyadic data, there was no gender difference in marital satisfaction but (2) when using nondyadic data, the gender difference was significant but women only reported slightly lower levels of marital satisfaction than men.

The present study builds on the previous studies conducted by Brown et al. (2017) and Jackson et al. (2014) to analyze how relationship happiness and disillusionment vary among union type and between partners. This analysis will combine the two previous studies by examining gendered differences in the effect of union type on relationship quality. In other words, we examine whether the effect of each union type on relationship quality is significantly different between males and females. 


\section{HYPOTHESES}

In this analysis, I formulate three hypotheses to examine the various effects that union type has on a couple's relationship quality.

H1: Married couples will experience higher levels of relationship happiness and lower levels of disillusionment than cohabiting couples.

Previous research has shown that cohabitors in general report poorer relationship quality than their married counterparts (Nock, 1995; Brown \& Booth, 1996). Specifically, cohabitors' mean level of happiness was lower and their mean level of disillusionment was higher than that of married couples (Neihuis, Reifman, \& Lee, 2015). Since marriage has existed for centuries, there are set social norms about how each partner should act and what they should expect from the union. Cohabitation has not been as normalized as marriage and therefore has less social norms to tell individuals what to expect from the union. Research has shown that men and women express different expectations for cohabiting relationships that suggest a substantial gender gap in the perceived role of cohabitation in the union formation process (Huang, et al., 2012). This lack of set social norms and differing expectations will result in higher levels of disillusionment and lower levels of happiness for cohabiting couples than their married counterparts. With this 
hypothesis, I plan to test this theory that married couples experience higher levels of relationship quality than their cohabiting counterparts.

H2: Couples who married directly will have the highest level of relationship happiness and lowest levels of relationship disillusionment, followed by couples who married with premarital cohabitation, cohabiting couples with plans to marry, and finally cohabiting couples without plans to marry.

Following Brown et al. (2017), we go beyond the marriage-cohabitation dichotomy and examine differences in relationship quality within the married group based on their cohabitation experiences and within the cohabiting group based on their plans to marry. Not only do I expect to find differences between married couples and cohabiting couples in general, I also expect to find differences within married couples based on their cohabitation experience and within cohabiting couples based on their plans to marry. Studies have shown that cohabiting premaritally is related to a decrease in marriage satisfaction (DeMaris \& Leslie, 1984; Brown et al., 2017). Additionally, having plans to marry is related to an increase in relationship quality among cohabiting partners (Brown, Manning \& Payne, 2017). Research has also shown that long-term cohabiting couples reported lower relationship happiness than other types of couples (Skinner, et al., 2002). With this hypothesis, I plan to test this theory that relationship quality varies within marriages based on cohabitation experience and within cohabiting unions based on plans to marry. 
H3: The effect of union type on relationship happiness and disillusionment is greater for women than it is for men.

In the previous work done on union type and relationship quality, researchers disagree on whether gender affects an individual's perceived relationship quality. Brown and Booth on one hand, did not find any gender differences in regard to relationship quality (1996). On the other hand, Niehuis, Reifman, and Lee found that women consistently reported greater levels of disillusionment than did men (2015.) In terms of marital satisfaction, Jackson et al. found that women and men in dyadic samples did not report different levels of satisfaction but women in nondyadic samples did report significantly lower levels than men (2014). With this hypothesis, I plan to test (1) whether the Jackson et al. finding of no difference in relationship quality for dyadic samples holds for this sample and (2) whether that same finding extends to cohabiting relationships. 


\section{METHODS}

\section{Data and Sample}

This study is conducted through a secondary data analysis. Data is obtained through the Married and Cohabiting Couples (MCC) survey conducted in 2010 by the National Center for Family and Marriage Research in collaboration with the survey research firm Knowledge Network (KN) (ICPSR 31333, 2010). The MCC was an Internet-based survey conducted from July 26, 2010 to October 13, 2010 on a national sample of heterosexual couples, both married and cohabiting. The KN firm maintains a national panel of approximately 50,000 people originating from probability-based address sampling and random digit dialing. The panel members are randomly recruited by telephone and by self-administered mail and web surveys. The panel covers both the online and offline populations in the U.S. Additionally, an oversample is conducted among telephone exchanges that have high concentrations of African-American and Hispanic households based on Census data.

The survey was first administered to 1,500 married men of whom 1,060 completed it. The wives of those who completed the survey were also administered a survey. Of these women, 752 completed it. The survey was then administered to 266 men in cohabiting relationships of whom 159 completed it. All the female partners of the men were then administered the survey. Of these women, 108 completed it. Since the number 
of cohabiting individuals was small compared to the number of married individuals, a second wave of surveys was distributed in the hopes of compensating for the small number. The second wave of surveys was administered to cohabiting couples in which only one partner was a member of the panel. Surveys were also administered to an opt-in panel recruited from online ads. After all survey methods were complete, the cohabiting subgroup consisted of 323 couples or 646 individuals. The married subgroup consisted of 752 couples or 1,504 individuals.

Following Brown et al. (2017), I dropped cases for missing data and limited my sample to only couples who have been in their current union for ten years or less. Analyzing data from couples who have been in their current union for 10 years or less serves two important purposes. First, it provides us with a recent cohort of married and cohabiting couples to ensure our data is current and accurate. Second, it increases comparability between the two union types considering the average duration of cohabitations is one to two years while the average duration of marriages is approximately 20 years. After these cases were excluded, I ended up with a final sample size of 630 individuals or 315 couples. The sample was divided into 270 married individuals or 135 married couples and 360 cohabiting individuals or 180 cohabiting couples.

\section{Measures}

\section{Dependent Variables}

The first dependent variable in this analysis is relationship happiness. On the MCC survey, individuals were asked to rate their relationship with their current spouse or partner on a 10-point scale, 1 representing "completely unhappy" and 10 representing 
"completely happy". These 1-10 ratings given by the individuals comprise the relationship happiness variable.

The second dependent variable in this analysis is relationship disillusionment. In correspondence with the study conducted by Brown et al., I define relationship disillusionment as a feeling of disappointment in one's relationship or partner resulting from the discovery that it is not what they had expected (2017). This variable is created from 11 survey items focusing on partner or relationship disillusionment. All 11 items are measured on a 5-point agreement scale, 1 representing "strongly disagree" and 5 representing "strongly agree". Therefore, a higher number on the scale represents greater relationship disillusionment. The items include statements such as "life together is not as enjoyable as I had expected" and "my relationship hasn't gone as perfectly as I thought it would". I created the variable relationship disillusionment by taking the average of all 11 item scores.

\section{Independent Variable}

The independent variable in this analysis is union type. This variable consists of four categories: married without premarital cohabitation, married with premarital cohabitation, cohabiting with plans to marry, cohabiting without plans to marry. Nearly all the cohabiting partners agree on whether they planned to marry their partners. Fourteen couples did not report the same answer on whether they planned to marry their current partner. In addition, nearly all the married couples give the same report regarding whether they cohabited premaritally. Only three couples did not report the same answer on whether they cohabited before marriage. I assume the disparity in responses within married couples to this question is due to the social desirability factor of having married 
directly. All couples who did not report the same union type were dropped from the analysis.

\section{Controls}

Control variables for this analysis include the following individual level variables: education, age, race, and previous marital experience. Education is coded into three dummy categories: high school degree or less (reference), some college, and bachelor's degree or higher. Age was coded as an interval variable with values ranging between 18 and 63. Race is coded into a dummy variable ( $1=$ White, $0=$ Non-White). Previous marital experience is coded as an interval variable based on how many times the individuals had been married prior to their current union. I also include the following couple-level variables as controls: relationship duration, household income, presence of children, educational heterogamy, employment heterogamy, age heterogamy, and race heterogamy. Relationship duration represents the number of years the couple has been together, created by subtracting the year the couple started dating from 2010 which is when the survey was administered. It ranged from 0 to 10 years. Household income represents the income bracket of the household ranging from $1=$ "less than $\$ 5,000$ " to 19 $=$ “\$175,000 or more". Number of children is coded as an interval variable representing the number of children (both biological and step) the couple has. Educational heterogamy is coded into three dummy variables: woman has higher educational attainment than man, man has higher educational attainment than woman, and homogamous educational attainment (reference). Employment heterogamy is coded into three dummy categories: man employed and woman unemployed, woman employed and man unemployed, both partners employed (reference). Age heterogamy is coded into three dummy variables 
consistent with the study conducted by Brown et al.: man older (man was 5 or more years older than the woman), woman older (woman was 2 or more years older than the man), same age (woman was less than 2 years older than the man and the man was less than 5 years older than the woman; reference) (2017). Race heterogamy is dummy coded (1= different race, $0=$ same race). The goal of including these controls in the models is to minimize confounding variables and ensure that the differences detected are due to varying union types.

\section{Analytic Strategy}

I began the analysis by reshaping the data from individual level to couple level data. This process paired individuals with their partners to create one observation for each couple. I then estimated the means (or proportions) of all variables used in the analyses for each gender by union type. I used t-tests to analyze significant differences across the four union types for all variables.

Next, I used ordinary least squares (OLS) regression to create four different models estimating the effects of union type on women's and men's relationship happiness and disillusionment. The first regression model estimates relationship happiness for men. The second regression model estimates relationship happiness for women. The third model estimates relationship disillusionment for men. Finally, the fourth model estimates relationship disillusionment for women.

I then used seemingly unrelated regression (SUR) models to further estimate the effects of union type on women's and men's relationship happiness and disillusionment. SUR models take into consideration that regressions for the two sample groups, men and 
women, have correlated error terms since the data are paired by couple. In other words, SUR models control for within-couple correlation of unobserved variables. 


\section{RESULTS}

\section{Descriptive Results}

Table 1 shows the means (or proportions) of all variables used in the analysis. The sample contained $41 \%$ married couples and 59\% cohabiting couples. More specifically, $14 \%$ were married couples who did not cohabit premaritally, $27 \%$ were married couples who did cohabit premaritally, $36 \%$ were cohabiting couples with plans to marry, and $23 \%$ were cohabiting couples without plans to marry. Approximately $85 \%$ of our sample had experience cohabiting. This is a higher percentage than previously reported which validates the theory developed by Brown, Manning, and Payne that cohabitation is a Ushaped phenomenon and is continuing to increase in occurrence (2017).

Relationship happiness varied by relationship type for both men and women which is represented in Table 1. Among women, those who married directly reported the highest relationship happiness, followed by those who were married after having cohabited, those who were cohabiting with plans to marry, and finally whose were cohabiting without plans to marry. The same trend emerged among the men. I used t-tests to compare happiness across union type for both males and females. Among women, the happiness rating of those cohabiting without plans to marry was significantly lower than all three of the other union types. Therefore, women who cohabit without plans to marry their partner tend to be less happy in their relationship than all the other union types. 
Among men, the happiness rating between the same union types were statistically significant. Similarly, men who cohabit without plans to marry their partner tend to less happy in their relationship than all other union types. This supports findings in the previous literature that claim that those who cohabit without plans to marry report the lowest levels of relationship quality. As Brown et al. stated, this could be due to varying meanings and expectations of cohabitation among different societal groups (2017).

Relationship disillusionment also varied by relationship type for both men and women as shown in Table1. Among women, those who were cohabiting without plans to marry experienced the greatest amount of disillusionment, followed by those who were cohabiting with plans to marry, those who were married after having cohabited, and finally those who married directly. A slightly different trend appeared among the men. For men, those who were cohabiting without plans to marry experienced the greatest amount of disillusionment, followed by those who were married after having cohabited, cohabiting couples with plans to marry, and finally those who married directly. I used ttest to analyze the statistical comparisons of disillusionment across union type for both males and females. Among women, the disillusionment rating was statistically significant between the following union types: (1) married directly and cohabiting with plans to marry, (2) married directly and cohabiting without plans to marry, and (3) married with cohabitation and cohabiting without plans to marry. Therefore, women who marry directly tend to experience less disillusionment than both types of cohabitors and women who marry with having cohabited premaritally tend to experience less disillusionment than cohabitors without plans to marry. This supports previous literature that found those who cohabit without plans to marry experience lower levels of relationship quality than 
all other union types. Among men, the disillusionment rating of men in cohabiting relationship without plans to marry was significantly higher than men in all three of the other union types. Therefore, men who cohabit without plans to marry tend to experience a greater sense of disillusionment and all of the other union types in this study. For both men and women, those who cohabit without plans to marry report significantly higher levels of relationship disillusionment which supports findings in previous literature. Similar to relationship happiness trends, this could be due to varying meanings and expectations of cohabitation among different societal groups (Brown et al., 2017).

The other individual level variables as well as the couple level and heterogamy variables varied across union types in the following ways. Men and women who married directly had the highest average level of education, whereas the other three groups were fairly similar in education. This is important to note considering education is positively associated with relationship quality (Skinner et al., 2002). Men and women who were cohabiting without plans to marry were older, on average, than those of the other three union types. Those who were cohabiting without plans to marry had the highest number of previous marriages, on average, then those of the other three union types. This supports previous literature that claimed more recent declines in rates of individuals who remarry are fully compensated for by the increasing rates of cohabitation (Brown, 2000). Those who were married, regardless of cohabitation experience, had a higher average household income than those in cohabiting unions. This supports the claim made by Cherlin that while marriage is decreasing in practical value, it is increasing as a status symbol (2004). For example, marriage is increasingly important in explaining the rising inequality in the U.S. given higher income people are more likely to marry other higher 
income people (Cherlin, 2004). Relationship duration was longer on average for married couples, regardless of cohabitation experience, then cohabiting couples. This was expected considering the average duration of marriages is 20 years while the average duration of cohabitations is one to two years (Brown et al., 2017). Those who were cohabiting without plans to marry had less children on average than those of the other three union types. Those who were cohabiting without plans to marry had a higher proportion of couples with varying educational attainment while the other three union types were similar in terms of educational heterogamy. Those who married directly had a lower proportion of dual working couples while the other three union types were similar regarding employment heterogamy. Those who were cohabiting without plans to marry had the highest proportion of couples with a significant age difference. The other three union types were similar regarding age heterogamy. Finally, the proportion of couples who were bi-racial was similar across all four union types. 


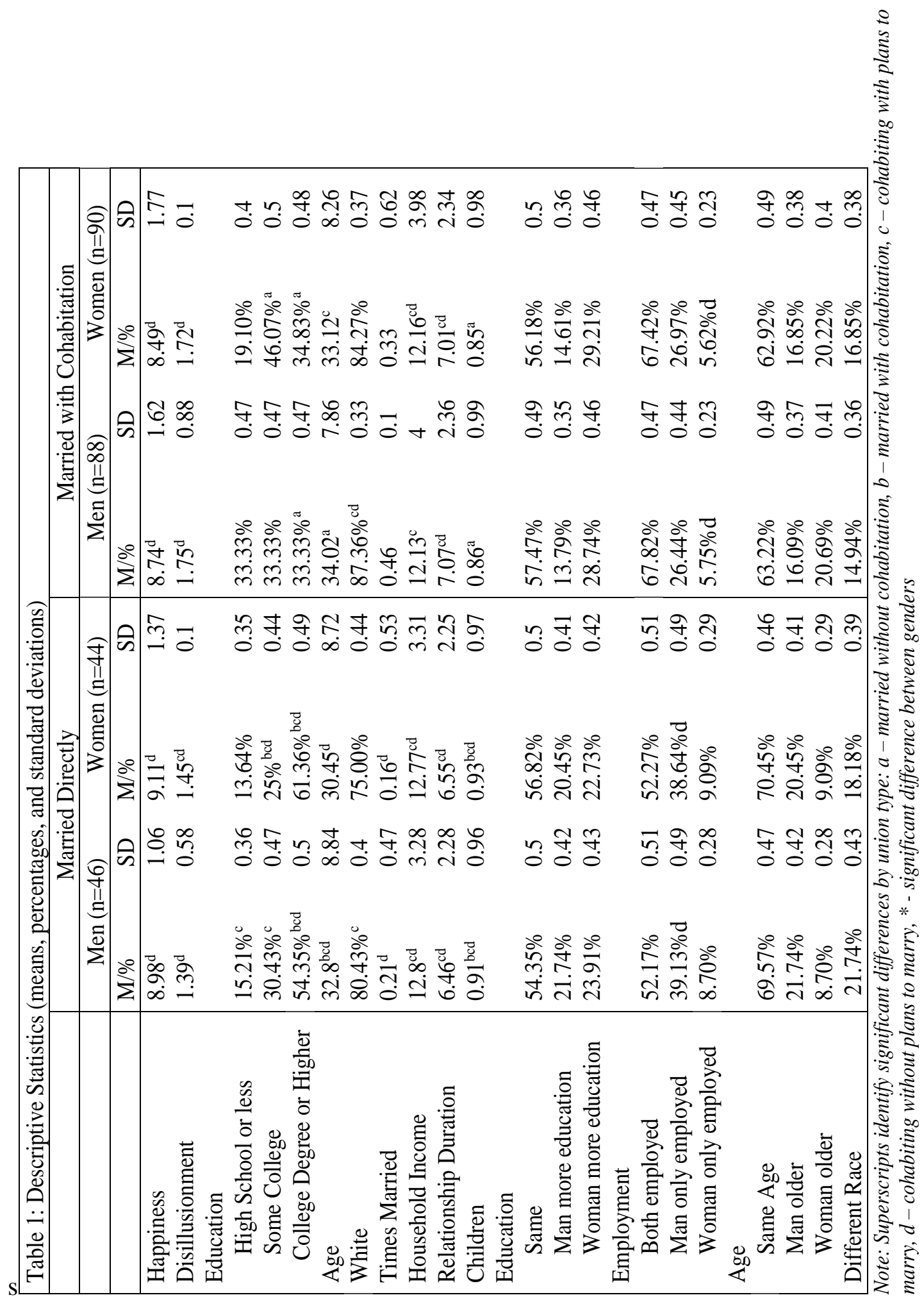




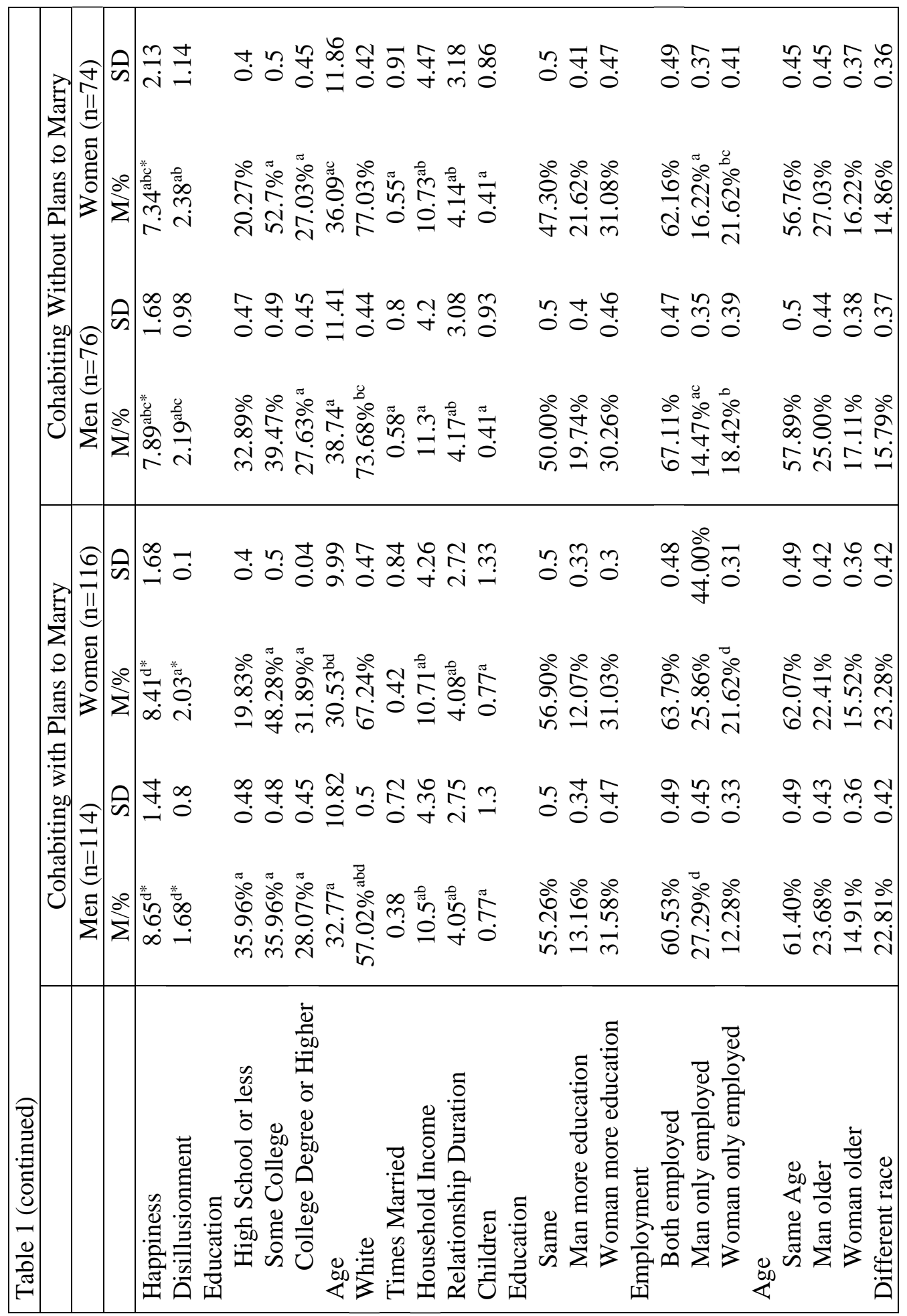




\section{Regression Results}

A preliminary analysis with OLS produced estimates that are largely consistent with my hypotheses. Regression diagnostics revealed violations of the OLS assumptions such as normality and homoscedasticity of errors. The results from my main analysis with the SUR (which are based on OLS) reported below thus must be interpreted with caution.

The reference group for all SUR models was individuals who married directly.

Table 2 shows the results from the SUR models. Model 1 shows the bivariate association between effect of union type and male relationship happiness without taking into consideration any control variables. This model is used as a comparison for Model 2 which shows the full model for the effects of union type on male happiness including all controls. The effect of union type on male happiness presented in the bivariate association persists in the full model. On average, men who cohabit without plans to marry experience a level of relationship happiness that is approximately 1.01 points lower than men who marry directly. Men who cohabit with plans to marry and men who marry having cohabiting premaritally do not experience levels of relationship happiness that are significantly lower than men who married directly. None of the control variables were significant in this model.

Model 1 also shows the bivariate association between union type and female happiness without taking any control variables into consideration. Again, this model is used as a comparison for Model 2 which displays the full model for the effect of union type on female happiness including all controls. Almost all effects of union type on female happiness presented in the bivariate model persisted in the full model. The only difference in the models was that in the full model, women who married with premarital 
cohabitation no longer experienced a significantly lower level of relationship happiness than those who marry diractly. The effects that did persist show that on average, women who cohabit without plans to marry experience a level of relationship happiness that is approximately 1.81 points lower than women who marry directly. In addition, women who cohabit with plans to marry experience a level of relationship happiness that is approximately .74 points lower than women who marry directly. The couple's total number of children was the only significant control variable in this model. Specifically, for each additional child a couple has, female relationship happiness decreases by approximately .29 points.

Model 3 displays the bivariate association between union type and male disillusionment without taking into consideration any control variables. This model is used as a comparison for Model 4 which shows the full model of the effects of union type on male disillusionment including all control variables. Almost all effects found in the bivariate association persisted in the full model. The only difference in the models was that in the full model, men who cohabited with plans to marry no longer experienced a level of relationship disillusionment that was significantly lower than men who married directly. The effects that did persist show that one average, men who cohabit without plans to marry experience a level of relationship disillusionment that is approximately .77 points higher than men who married directly. In addition, men who married with premarital cohabitation experience a level of relationship disillusionment that is approximately .39 points higher than men who marry directly. Two control variables were significant in this model: number of previous marriages and total number of children. Specifically, for each additional increase in the number of marriages a man has experienced, his level of 
relationship disillusionment decreases by approximately .12 points. In addition, for each additional child a couple has, male relationship disillusionment increases by approximately .10 points.

Model 3 also displays the bivariate association between union type and female relationship disillusionment without considering any control variables. Again, this model is used as a comparison for Model 4 which shows the full model of the effect of union type on female relationship disillusionment containing all control variables. All of the effects found in the bivariate association persisted in the full model. Specifically, women who cohabit without plans to marry experience a level of relationship disillusionment that is approximately .98 points higher than women who marry directly. In addition, women who cohabit with plans to marry experience a level of relationship disillusionment that is approximately .51 points higher than women who marry directly. The total number of children was the only significant control variable in this model. For each additional child a couple has, the level of female disillusionment increases by approximately .15 points. 


\begin{tabular}{|c|c|c|c|c|}
\hline & \multicolumn{2}{|c|}{ Model 1} & \multicolumn{2}{|c|}{ Model 2} \\
\hline & \multicolumn{4}{|c|}{ Happiness } \\
\hline Variable & $\begin{array}{c}\text { Men } \\
\text { Coef(SE) }\end{array}$ & $\begin{array}{l}\text { Women } \\
\text { Coef(SE) }\end{array}$ & $\begin{array}{c}\text { Men } \\
\text { Coef(SE) }\end{array}$ & $\begin{array}{c}\text { Women } \\
\text { Coef(SE) }\end{array}$ \\
\hline Married with Cohabitation & $-0.23(.25)$ & $-0.64(.30)^{*}$ & $-0.25(.25)$ & $-0.64(.30)$ \\
\hline Cohabiting with Plans to Marry & $-0.17(.24)$ & $-0.58(.29)^{*}$ & $-0.15(.26)^{\dagger}$ & $-0.74(.31)^{* \dagger}$ \\
\hline Cohabiting without Plans to Marry & $-.98(.26)^{* * *}$ & $-1.61(.32)^{* * *}$ & $-1.01(.28)^{* * *+}$ & $-1.80(.34)^{* * * \dot{\dagger}}$ \\
\hline Previous Marriages & & & $0.13(.09)$ & $0.18(.11)$ \\
\hline Household Income & & & $0.02(.02)$ & $-0.00(.03)$ \\
\hline Relationship Duration & & & $0.01(.03)$ & $-0.03(.03)$ \\
\hline Number of Children & & & $-0.06(.07)$ & $-0.29(.09)^{* *}$ \\
\hline Educ: Some College & & & $-0.22(.19)$ & $0.18(.25)$ \\
\hline Educ: Degree or Higher & & & $-0.10(.27)$ & $0.16(.32)$ \\
\hline Educ: Man More & & & $0.17(.24)$ & $-0.57(.29)$ \\
\hline Educ: Woman More & & & $0.08(.21)$ & $-0.32(.22)$ \\
\hline Employed: Man Only & & & $0.18(.19)$ & $-0.03(.23)$ \\
\hline Employed: Woman Only & & & $-0.05(.26)$ & $-0.34(.31)$ \\
\hline Age: Man Older & & & $-0.35(.19)$ & $-0.26(.23)$ \\
\hline Age: Woman Older & & & $-0.16(.22)$ & $-0.40(.27)$ \\
\hline Different Race & & & $-0.16(.21)$ & $0.18(.24)$ \\
\hline Constant & $8.96(.20)^{* * *}$ & $9.10(.25)^{* * *}$ & $8.94(.45)^{* * *}$ & $9.69(.50)^{* * *}$ \\
\hline
\end{tabular}

Note: $*$ - Significant difference by union type (reference $=$ married without cohabitation) $: *-p<.05, * *-p<.01$, $* * *-p<.001$; Significant difference by gender within each union type $(p<.05)={ }^{+}$ 


\begin{tabular}{|c|c|c|c|c|}
\hline \multirow[b]{3}{*}{ Variable } & \multicolumn{2}{|c|}{ Model 3} & \multicolumn{2}{|c|}{ Model 4} \\
\hline & \multicolumn{4}{|c|}{ Disillusionment } \\
\hline & $\begin{array}{c}\text { Men } \\
\text { Coef(SE) }\end{array}$ & $\begin{array}{c}\text { Women } \\
\text { Coef(SE) }\end{array}$ & $\begin{array}{c}\text { Men } \\
\text { Coef(SE) }\end{array}$ & $\begin{array}{c}\text { Women } \\
\text { Coef(SE) }\end{array}$ \\
\hline Married with Cohabitation & $0.34(.14)^{*}$ & $0.26(.16)$ & $0.39(.14)^{* *}$ & $0.26(.16)$ \\
\hline Cohabiting with Plans to Marry & $0.25(.13)$ & $0.46(.16)^{* *}$ & $0.25(.14)+$ & $0.51(.16)^{* *+}$ \\
\hline Cohabiting without Plans to Marry & $0.71(.14)^{* * *}$ & $0.87(.17)^{* * *}$ & $0.77(.15)^{* * *}$ & $.98(.18)^{* * *}$ \\
\hline Previous Marriages & & & $-0.12(.05)^{* *}$ & $-0.14(.06)$ \\
\hline Household Income & & & $-0.01(.01)$ & $-0.01(.01)$ \\
\hline Relationship Duration & & & $0.00(.02)$ & $0.01(.02)$ \\
\hline Number of Children & & & $0.10(.04)^{*}$ & $0.15(.05)^{* *}$ \\
\hline Educ: Some College & & & $0.18(.10)$ & $-0.13(.13)$ \\
\hline Educ: Degree or Higher & & & $-0.02(.14)$ & $-0.09(.17)$ \\
\hline Educ: Man More & & & $-0.03(.13)$ & $0.05(.15)$ \\
\hline Educ: Woman More & & & $-0.04(.11)$ & $0.12(.12)$ \\
\hline Employed: Man Only & & & $-0.05(.10)$ & $0.02(.12)$ \\
\hline Employed: Woman Only & & & $0.12(.14)$ & $0.09(.16)$ \\
\hline Age: Man Older & & & $0.07(.10)$ & $0.14(.12)$ \\
\hline Age: Woman Older & & & $-0.11(.12)$ & $0.22(.15)$ \\
\hline Different Race & & & $-0.05(.11)$ & $-0.03(.13)$ \\
\hline Constant & $1.45(.11)^{* * *}$ & $1.52(.13)^{* * *}$ & $1.43(.23)^{* * *}$ & $1.38(.27)^{* * *}$ \\
\hline
\end{tabular}




\section{Gendered Differences}

After performing the SUR models, I ran Wald-tests to see how the effect of union type on relationship happiness and disillusionment varied by gender. For relationship happiness, the effect of union type differed significantly for men and women in both groups of cohabiting unions. Specifically, for both cohabitors with plans to marry and cohabitors without plans to marry, the effect of union type on relationship happiness is stronger from women than it is for men. In other words, women's relationship happiness is more strongly affected by union type than men. In both type of marriages, those with previous cohabitation experience and those without, the effect of union type on relationship happiness did not differ significantly for men and women.

For relationship disillusionment, the effect of union type differed significantly for cohabitors with plans to marry. Specifically, for couples who cohabit with plans to marry, the effect of union type on relationship disillusionment is stronger for women than it is for men. In other words, women's relationship disillusionment is more strongly affected by union type than men. In both types of marriages, as well as for cohabitors without plans to marry, the effect of union type on relationship disillusionment did not differ significantly for men and women.

The findings regarding gendered differences for the relationship quality of marriages is consistent with previous literature (Jackson et al., 2014). Through our dyadic sample we found no gender difference in the relationship quality of marriages. This trend did not persist for cohabiting unions though. Despite the dyadic sample, gendered differences still occurred in the relationship quality of the cohabiting unions. 


\section{DISCUSSION}

Cohabitation continues to increase in popularity within the United States. As it does so, the role it plays in family life continues to shift. Cohabitation has become an important step in the dating process, regardless of whether couples are planning to marry. Our study used relatively current data, obtained in 2010, containing a national sample of married and cohabiting couples to examine whether relationship quality trends that were documented in the past decades persist or have diminished.

Drawing on the work of Brown et al. conducted in 2017 as well as the work of Jackson et al. conducted in 2014, I proposed three hypotheses about the linkages between union type and relationship quality. First, I hypothesized that married couples would experience higher levels of relationship happiness and lower levels of disillusionment than cohabiting couples. For both men and women, cohabiting couples experienced lower levels of relationship happiness than their married counterparts. For both men and women, cohabiting couples also experienced higher levels of relationship disillusionment than their married counterparts. Therefore, the data in this analysis supports my first hypothesis.

Second, I hypothesized that couples who married directly would have the highest level of relationship happiness and lowest levels of relationship disillusionment, followed by couples who married with premarital cohabitation, cohabiting couples with plans to 
marry, and finally cohabiting couples without plans to marry. Among women, couples who married directly had the highest level of relationship happiness and lowest levels of relationship disillusionment, followed by couples who married with premarital cohabitation, cohabiting couples with plans to marry, and finally cohabiting couples without plans to marry. Among men, the same trend existed among their levels of relationship happiness, however their levels of disillusionment followed a slightly different trend. Among men, couples who married directly had the lowest levels of relationship disillusionment, followed by cohabiting couples with plans to marry, married couples with premarital cohabitation, and finally cohabiting couples without plans to marry. Therefore, my second hypothesis is supported by female happiness, female disillusionment, and male happiness, however it is only partial supported by male disillusionment.

Finally, I hypothesized that the effect of union type on relationship happiness and disillusionment would be greater for women than for men. The effect of union type on relationship happiness differed significantly between men and women for both types of cohabitors, those with plans to marry and those without plans to marry. The effect of union type on relationship disillusionment differed significantly between men and women for only cohabitors with plans to marry. In addition, the effect of union type on relationship happiness and disillusionment did not vary between men and women for either type of marriage. Therefore, my third hypothesis was supported by cohabiting unions, but not by marriages.

Overall, this study has shown that on average, cohabitors report lower levels of relationship quality, especially those without plans to marry. Within cohabiting unions, 
women tend to report lower levels than their male partners. These findings controlled for the number of children in the union which is negatively associated with relationship quality. The question now stands, what makes women in cohabiting unions report lower levels of relationship happiness than both their male partners and their married counterparts? Previous research conducted by Huang et al. (2012) found that men and women in cohabiting unions express different expectations for the union, suggesting a "substantial gender gap in the perceived role of cohabitation in the union formation process." Specifically, "love" was offered as a motivation to cohabit three times more frequently for women than it was for men (Huang et al., 2012). In addition, women are more likely to view cohabitation as a "transitional arrangement to proceed marriage to the same partner" (Huang et al., 2012). On the other hand, Leonhardt et al. (2020), found that both men and women saw marriage as a want rather than a need. In addition, both men and women expressed multiple factors that would hold them back from marriage (Leonhardt et al., 2020). While these factors were different for men and women, it showed that emerging adults tend to take the decision to marry very seriously. Given the findings of these two studies, I propose that the significantly lower levels of relationship quality reported by females in cohabiting unions is due to varying expectations between partners regarding the union and a lack of serious decision-making involved in entering a cohabiting union. Women tend to enter cohabiting unions out of love for their partner with the expectation that it is a temporary state on the path to marriage. Men, however, are less likely to be motivated by love and less likely to see cohabitation as a step in the path to marriage. Therefore, women are likely to have their expectations for cohabitation go unmet and consequently experience lower levels of relationship quality. In addition, 
both partners may not consider their entrance into cohabitation as seriously as they would entrance into a marriage, and therefore end up in less satisfying relationships.

This study contributes to the expanding literature focusing on the association between union type and relationship quality. I have not only shown that union type does have an effect on relationship quality, but I have also shown that these effects are gendered. Women's perceived relationship quality tends to be more effected by union type than men's perceived relationship quality. This is especially true for women in cohabiting unions. I propose that this difference in relationship quality is due to a difference of expectations between partners regarding their cohabiting union. Cohabiting unions are more susceptible to differing expectations between partners because there are fewer social norms dictating the union dynamics than in marriages.

\section{Limitations}

My study has some limitations. First, the MCC is a cross-sectional survey, and thus I am unable to establish whether cohabiting without a plan to marry is the cause or the consequence of being in a low-quality relationship. Future research will benefit from collection of national longitudinal data for dyadic analysis.

Another limitation of the current study is that the data only contained information on heterosexual couples. It is not surprising that homosexual couples were excluded considering the MCC survey was administered in 2010 which was before homosexual marriage become legal in all states. With homosexual marriages becoming more prevalent since its legalization in 2015 , it would be highly beneficial to examine their perceived relationship quality. 
homosexual couples vary by union type and how those levels compare to heterosexual couples. As a topic of further research, I would recommend analyzing relationship quality of homosexual couples by union type and in comparison with heterosexual couples.

The exclusion of religiosity in the data is another limitation of the current study. Previous research has shown that religiosity is strongly associated with union quality (Heaton \& Pratt, 1990; Arland, Axinn, \& Hill, 1992; Manning \& Smock, 2002; Stanley, Whitton, \& Markman, 2004; Reinhold, 2010; Manning, Smock, Dorius, \& Cooksey, 2014). It would have been beneficial to examine individuals' level of religiosity, how it varies by union type, and how it affects their perceived relationship quality. As a topic for further research, I would recommend adding a variable to measure religiosity. 


\section{CONCLUSION}

As cohabitation continues to rise in occurrence, it is also rising in popularity within the research world. Numerous studies have been conducted on cohabitation and its place in the family life course. This study contributes to that growing literature by analyzing the gendered effects of union type on relationship quality. I use data from the recent Married and Cohabiting Couple (MCC) survey administered in 2010. Given that this data is coupled, I combined partnered into one observation so I could examine gender difference within couples. I then conducted several t-tests, OLS regression, and SUR models to test the effects of union type on relationship quality for men and women. My results supported previous literature that found that on average, cohabitors report lower levels of relationship quality than their married counterparts. More specifically, my results supported previous findings that those who marry without cohabitation have the highest levels of relationship quality, followed by those who marry with cohabitation and those who cohabit with plans to marry, and lastly those who cohabit without plans to marry. This study also added to literature by analyzing gendered difference among the effects of union type on relationship quality. On average, union type has a larger effect on women's relationship quality than men's. These findings contribute to the broader discussion about cohabitation and its place in the family life cour 


\section{REFERENCES}

Axinn, William G. \& Arland Thornton. 1992. "The Relationship between Cohabitation and Divorce: Selectivity or Casual Influence.” Demography. 29(3). 357-374.

Brine, Julie \& Kara Joyner. 1999. “The Ties That Bind: Principles of Cohesion and Cohabitation and Marriage.” American Sociological Review. 64(3). 333-355.

Brown, Susan L. \& Alan Booth. 1996. “Cohabitation versus Marriage: A Comparison of Relationship Quality.” Journal of Marriage and Family. 58(3). 668-678.

Brown, Susan. 2000. “Union Transitions Among Cohabitors: The Significance of Relationship Assessments and Expectations.” Journal of Marriage and Family. 62. 833-846.

Brown, Susan L, Wendy D. Manning, \& Krista K. Payne. 2017. "Relationship Quality Among Cohabiting Versus Married Couples.” Journal of Family Issues. 38(12) 1730 $-1753$.

Cherlin, Andrew J. 2004. “The Deinstitutionalization of American Marriage.” Journal of Marriage and Family. 66(4).

Cherlin, Andrew J. 2009. The Marriage Go-Round: The State of Marriage and the Family in America Today. New York: Vintage Books.

Cohan, Catherine L. \& Stacy Kleinbaum. 2002. "Toward a Greater Understanding of the Cohabitation Effect.” Journal of Marriage and Family. 64(1). 180-192. 
Cunningham, Mick \& Arland Thornton. 2005. "The Influence of Union Transitions on White Adults' Attitudes toward Cohabitation.” Journal of Marriage and Family. 67(3). 710720.

DeMaris, A, \& G. R. Leslie. (1984). "Cohabitation with the Future Spouse: Its Influence upon Marital Satisfaction and Communication. Journal of Marriage and the Family. (46) $77-84$.

Hayford, Sarah \& S. Phillip Morgan. 2008. “The Quality of Retrospective Data on Cohabitation.” Demography. 45(1). 129-141.

Heaton, Tim B. \& Edith L. Pratt. 1990. "The Effects of Religious Homogamy on Marital Satisfaction and Stability." Journal of Family Issues. 11(2). 191-207.

Huang, Penelope M., Pamela J. Smock, Wendy D. Manning, \& Cara a. Bergstrom-Lynch. 2012. "He Says, She Says: Gender and Cohabitation.” Journal of Family Issues. 32. 876-905.

Jackson, Jeffrey B., Richard B. Miller, Megan Oka, Ryan G. Henry. 2014. "Gender Differences in Marital Satisfaction: A Meta-Analysis." Journal of Marriage and Family. 76. 105-129.

Jose, Anita, K. Daniel O’Leary, \& Anne Moyer. 2010. “Does Premarital Cohabitation Predict Subsequent Marital Stability and Marital Quality? A Meta Analysis.” Journal of Marriage and Family. 72(1).

Leonhardt, Nathan D., Brian J. Willoughby, Jason S. Carroll, Shelby Astle, \& Joshua Powner. 2020. "We want to be married on our own terms," non-university emerging adults' marital beliefs and differences between men and women." Journal of Family Studies 
Macklin Eleanor D. 1972. "Heterosexual Cohabitation among Unmarried College Students." The Family Coordinator. 21(4). 462-472.

Manning, Walter \& Pamela Smock. 2002. "First Comes Cohabitation and Then Comes Marriage? A Research Note.” Journal of Family Issues. 23(8). 1065-1087.

Manning, Wendy \& Jessica Cohen. 2012. "Premarital Cohabitation and Marital Dissolution: An Examination of Recent Marriages." Journal of Marriage and Family. 74(2).

Manning, Wendy, Pamela Smock, Cassandra Dorius, \& Elizabeth Cooksey. 2014. "Cohabitation Expectations Among Young Adults in the United States: Do They Match Behavior?" Population Research and Policy Review. 33(2). 287-305.

Neihuis, Sylvia, Alan Reifman, \& Kyung-Hee Lee. 2013. "Disillusionment in Cohabiting and Married Couples: A National Study.” Journal of Family Issues.

Nock, S.L. 1995. “A Comparison of Marriages and Cohabiting Relationships.” Journal of Family Issues. 16(1). 53-76.

Nomaguchi, Kei \& Melissa A. Milkie. 2015. “Gender, Accuracy About Partners’ WorkFamily Conflict, and Relationship Quality." Gender and the Work-Family Experience: An Intersection of Two Domains. New York: Springer International Publishing.

Phillips, J.A. \& M. M. Sweeney. 2005. "Premarital Cohabitation and Marital Disruption Among White, Black, and Mexican American Women. Journal of Marriage and Family. 67(2). 296-314.

Reinhold, Steffen. 2010. "Reassessing the Link Between Premarital Cohabitation and Marital Instability." Demography. 47(3). 719-733 
Skinner, Kevin B., Stephen J. Bahr, D. Russell Crane, \& Vaughn R. Call. 2002.

“Cohabitation, Marriage, and Remarriage: A Comparison of Relationship Quality Over Time.” Journal of Family Issues. 23(1). 74-90.

Smock, Pamela A. 2000. "Cohabitation in the United States: An Appraisal of Research Themes, Findings, and Implications.” Annual Review of Sociology. 26(1). 1-20.

Stanely, Scott M., Sarah W. Whitton, \& Howard J. Markman. 2004. "Maybe I Do: Interpersonal Commitment and Premarital or Nonmarital Cohabitation.” Journal of Family Issues. 25(4). 496-519.

Steuber, Keli Ryan, \& Anthony Paik. 2013. "Of Money and Love: Joint Banking, Relationship Quality, and Cohabitation.” Journal of Family Issues. 35(9). 1154-1176.

Thornton, Arland, William G. Axinn, \& Yu Xie. 2007. Marriage and Cohabitation. Chicago: The University of Chicago Press.

Thorton, Arland, William G. Axinn, \& Daniel H. Hill. 1992. "Reciprocal Effects of Religiosity, Cohabitation, and Marriage.” American Journal of Sociology. 98(3).

Waite, Linda J \& Maggie Gallagher. 2000. The Case for Marriage. New York: Random House.

Vespa, Jonathan \& Matthew A. Painter II. 2011. "Cohabitation History, Marriage, and Wealth Accumulation.” Demography. 48(3). 983-1004. 


\section{CURRICULUM VITA}

NAME: $\quad$ Courtney Michelle Lush

ADDRESS: Department of Sociology

113

University of Louisville

Louisville, KY, 40208

DOB: $\quad$ Louisville, Kentucky - February 23, 1996

EDUCATION

\& TRAINING: $\quad$ B.S., Statistics

Eastern Kentucky University

2014-18

B.A., Sociology

Eastern Kentucky University

2014-18

M.A., Sociology

University of Louisville

2018-20

AWARDS: $\quad$ Eastern Kentucky University Founders Award, 2014

Eastern Kentucky University Department of Anthropology, Sociology, and Social Work Award Recipient, 2018

University of Louisville Faculty Favorite Nominee, 2019

PROFESSIONAL

SOCIETIES: $\quad$ Sociologists for Women in Society - South

American Statistical Association

PUBLICATIONS: $\quad$ Lush, Courtney, James N. Maples, and Michael Bradley. 2017.

"Locavore Purchasing Habits of Big Turtle 50 Miler 
Ultramarathon Event." Submitted to race organizer Michael Whisman on August 1, 2017.

Maples, James, Michael Bradley, Ryan L. Sharp, Courtney Lush, Erina Mori, and David Wagers. 2017. "Economic Impact of the 2017 Big Turtle 50 Miler.” Submitted to race organizer Michael Whisman on June 1, 2017.

Maples, James N, Courtney Lush, and Elizabeth Underwood. 2017. "Appalachian Research and Defense Fund of Kentucky: 2017 User Study." Submitted to Robert Johns, AppalReD Director, on July 1, 2017.

Lush, Courtney, James N. Maples, and Elizabeth Underwood. 2017. "Appalachian Research and Defense Fund of Kentucky: 2017 Professional Study." Submitted to Robert Johns, AppalReD Director, on July 1, 2017. 